\title{
Valores, Ética e Julgamento Moral: Um Estudo Exploratório em Empresas Familiares
}

\author{
Janine Kieling Monteiro ${ }^{1}$ \\ Fabiana Cobas do Espirito Santo \\ Franciela Bonacina \\ Universidade do Vale do Rio dos Sinos, São Leopoldo
}

\begin{abstract}
Resumo
Este estudo investigou princípios éticos, valores morais e julgamento moral nas empresas familiares. Participaram 2 empresas gaúchas, com 28 participantes cada. Utilizou-se questionário e MJI. A metodologia foi análise de conteúdo e de freqüência. Os principais resultados foram: ambas empresas possuem código de ética que é conhecido. Foi citado que a má conduta deve ser denunciada, que ambas empresas adotariam medidas corretivas, apesar da punição ser desigual. As infrações mais cometidas foram: mentira, roubo, assédio sexual, consumo de drogas durante expediente, contratação por indicação de pessoas não-qualificadas, informações escondidas sobre empresa, controle de recados e $e$ mails e exigência de horas-extras sem pagamento adicional. Foram destacados valores como responsabilidade, respeito e honestidade. Não encontramos diferenças significativas no julgamento moral.
\end{abstract}

Palavras-chave: Ética empresarial; valores; julgamento moral.

Values, Ethics and Moral Judgment: An Familiar Business Exploratory Study

\begin{abstract}
This paper has investigated ethical principals, moral values and moral judgements into family business. Two gaúcha business, with 28 people each, have participated in. It was utilized a questionnaire and MJI. The methodology used was the analyses of content and frequency. The main results were: both business have code of ethics and it common knowledge. It was said that bad behavior must be revealed and both business would adopt corrective measures despite the fact that punishment is unequal. The transgressions that have been committed the most were: lie, stealing, sexual harassment, use of drugs during office hours, hiring unqualified people by indication, hidden information about the company, messages and e-mails control and requirement of overtime without payment. Values, responsibility, respect and honesty have been highlighted. Significant differences in moral judgment not been founded.

Keywords: Ethical business; values; moral judgment.
\end{abstract}

A preocupação com a ética e a moral utilizada nas empresas vem crescendo, desde o final do século XX (Ferrell, Fraedrich \& Ferrell, 2000/2001). Muitas empresas têm se preocupado em divulgar os seus valores e até, mais recentemente, várias empresas estão adotando um código de ética interno para nortear as práticas na organização. Diante da ambigüidade e da crescente complexidade das práticas empresariais contemporâneas - fruto das novas exigências de eficiência, inovação e competitividade, a reflexão ética serve de base para que se tenha coesão organizacional. Afinal, dilemas e incertezas aparecem de forma incessante e prever riscos torna-se cada vez mais difícil (Srour, 2000).

As decisões tomadas dentro das organizações não são neutras, quem decide faz escolhas entre diferentes cursos de ação e deflagra conseqüências, aí entra a reflexão ética. Não há como se desvincular moral e interesses na empresa, ou moral e pressões operadas pela sociedade. Assim, o importante não é saber se a empresa dispõe de uma "essência moral", mas se as conseqüências das decisões tomadas nesta são ou não benéficas para a maioria das partes envolvidas. As empresas não mais desempenham apenas uma função econômica, mas também uma função ética na sociedade.

A presente pesquisa teve como objetivo principal o estudo da ética e de valores morais que têm norteado a adoção de comportamentos e atitudes em organizações familiares com fins

\footnotetext{
${ }^{1}$ Agradecemos, in memoriam, à Dra Angela Maria Brasil Biaggio pelo apoio, incentivo e colaboração.

${ }^{2}$ Endereço para correspondência: Av. Unisinos, 950, CEP 93022 000, São Leopoldo, RS. Fone (51) 30281814; Fax: (51) 5908122. E-mail: janinekm@terra.com.br
}

lucrativos. E também procurou investigar a maturidade do julgamento moral de gestores e colaboradores nas empresas estudadas.

\section{Ética empresarial}

A ética estuda a moral, o dever fazer, a qualificação do bem e do mal, a melhor forma de agir coletivamente. Avalia os costumes e diz quais ações morais são moralmente válidas e quais não, tende a estabelecer os princípios de valorização e condução da vida. No que diz respeito a ética dentro das empresas, existem duas vertentes em questão: a ética pessoal e a ética empresarial.

A base teórica utilizada para enfocar a ética pessoal foi a de Weber (1959) que destaca duas teorias éticas: a ética da convicção (tratado dos deveres) e a ética da responsabilidade (estudo dos fins humanos).

Srour (2000, p. 51) destaca que a máxima da ética da convicção diz: "Cumpra suas obrigações" ou "siga suas prescrições". É uma ética pautada por valores e normas previamente estabelecidas, cujo efeito primeiro consiste em moldar as ações que deverão ser praticadas. Já a máxima da ética da responsabilidade diz que somos responsáveis por aquilo que fazemos. Exprime as expectativas que as coletividades nutrem. Parte do pressuposto de que os eventos desejados só ocorrerão se dadas decisões forem tomadas e se determinadas ações forem empreendidas. Para o mesmo autor, as duas éticas enfocam tipos diferentes de referências morais e configuram, de forma inconfundível, dois modos de decidir. Enquanto os agente que obedecem à ética da convicção guiam-se por imperativos de consciência, os que se orientam pela ética da responsabilidade guiam-se por uma análise de riscos.

A ética empresarial estaria relacionada a reflexões ou indagações sobre costumes e morais, isto é, qual a moral vigente nas empresas. 
Muito têm a ganhar as empresas que institucionalizam orientações efetivamente partilhadas sobre os seus membros ou que convencionam valores que foram previamente negociados. As normas de comportamento derivam dessas providências. Portanto, a reflexão ética torna-se um instrumento de trabalho simbólico: intervém de maneira útil no modus operandi das empresas e contribui para moldar sua identidade corporativa (Srour, 2000).

A ética empresarial reflete sobre as normas e valores efetivamente dominantes em uma empresa. Em sentido amplo, ela baseia-se na idéia de um contrato social segundo o qual os membros se comportam de maneira harmoniosa, levando em conta os interesses dos outros. Na ética empresarial podemos considerar como desejáveis todas as condições que uma empresa possa criar para aumentar e não diminuir a vida das pessoas em todas as suas dimensões. Isto exigiria um etos empresarial que sem considerar a rentabilidade, vise o lado humanitário, que diga sim à eficiência, mas inclua também a responsabilidade e o compromisso (Leisinger \& Schimitt, 2001).

Atualmente, o comportamento ético por parte da empresa é esperado e exigido pela sociedade. O único lucro moralmente aceitável é aquele obtido com ética. São também razões para a empresa ser ética: custos menores, a possibilidade de avaliar com precisão o desempenho da sua estrutura, a legitimidade moral para exigir comportamento ético dos empregados, a geração de lucro livre de contingências, a obtenção de respeito dos parceiros comerciais, o cumprimento de dever inerente à responsabilidade social da organização (Moreira, 1999).

A moral está relacionada a um sistema de normas que expressam valores, códigos formalizados, conjunto internamente coerente de princípios ou de propósitos socialmente validados, discursos que servem de modelo para as relações sociais e aos comportamentos dos agentes. As questões morais escondem-se em muitas decisões e ações do cotidiano empresarial, ainda que os dirigentes não tenham plena consciência disso. Cada vez mais, a imagem que as empresas gostariam de passar é a de empresas éticas. Isto, na verdade, implica em dizer empresas moralmente inatacáveis, sintonizadas com a moral do tempo e com os costumes vigentes. Por isso, empresas éticas seriam aquelas que subordinam as suas atividades e estratégias a uma prévia reflexão ética e agem de forma socialmente responsável. (Srour, 2000).

Por moral podemos entender determinadas normas que orientam o comportamento prático (sobretudo para com o próximo, mas também com a natureza e para consigo mesmo). A moral orienta-se por valores: as normas já pressupõe os valores..., o que as normas exigem é que os valores sejam realizados (Leisinger \& Schimitt, 2001, p. 18). Portanto, para esses autores, moral empresarial é o conjunto de valores e normas vinculadas dentro de uma determinada empresa. Para os mesmos autores, as tomadas de posição baseiam-se em vivências de pessoas individuais condicionadas pelo tempo, e por isso são extremamente diversas e ambivalentes. Já os valores são algo que possui unidade e perenidade; valores são as metas às quais a moral aspira - metas que conferem à moral um objetivo. Nas metas está situada a exigência normativa, a partir da qual a moral experimenta sua justificação ou desqualificação - ou simplesmente, seu objetivo.

Segundo Goulart (2002), podemos distinguir a moral do trabalho e a ética do trabalho, como expressão da dupla existência relacionada aos valores, o que nos permite entender a moral enquanto ideologia de dominação e a ética no trabalho como forma positiva de construção de uma sociabilidade efetivamente humana no interior da organização. Esta possibilidade de uma ética no trabalho pode ser ilustrada através de situações de trabalho como a distinção entre o trabalho prescrito e o real, a autonomia vigiada nas empresas e em situações sociais paradigmáticas como o "jeitinho brasileiro".

O que envolve tomar uma atitude ética dentro da empresa? As pessoas, com freqüência, supõe que tomar uma decisão ética na empresa se assemelha a forma com que agem na família ou na vida pessoal. No entanto, no contexto de trabalho, a maioria sofre pressões da empresa na hora de decidir sobre o que é melhor fazer. Ferrell e colaboradores (2000/2001) propõem um modelo estrutural (Figura 1) no processo da tomada de decisão, no qual os principais componentes seriam: a identificação da gravidade da questão ética, os fatores individuais, como desenvolvimento cognitivo moral, idade e sexo e a cultura da empresa.

Quanto à gravidade da questão ética, esta pode ser entendida como a sua relevância ou importância para pessoa, grupo de trabalho e/ou empresa. Assume um caráter pessoal na medida em que sofre a influência de valores, crenças, necessidades, maneira de ver as coisas, características especiais da situação e pressões pessoais e/ou institucionais. Os fatores individuais envolvem aspectos como o desenvolvimento cognitivo moral, também conhecido como o julgamento moral, a idade e o sexo.

A cultura da empresa, que pode ser definida como um conjunto de valores, convicções, metas, normas e maneiras de resolver os problemas na organização, pode sugerir nos seus colaboradores atitudes éticas ou antiéticas. Ferrell e colaboradores (2000/2001) acreditam que o modelo estrutural proposto acima serve de guia e para prover insights nas tomadas de decisões. Essas decisões não dependem somente da filosofia moral adotada pelo o indivíduo, mas

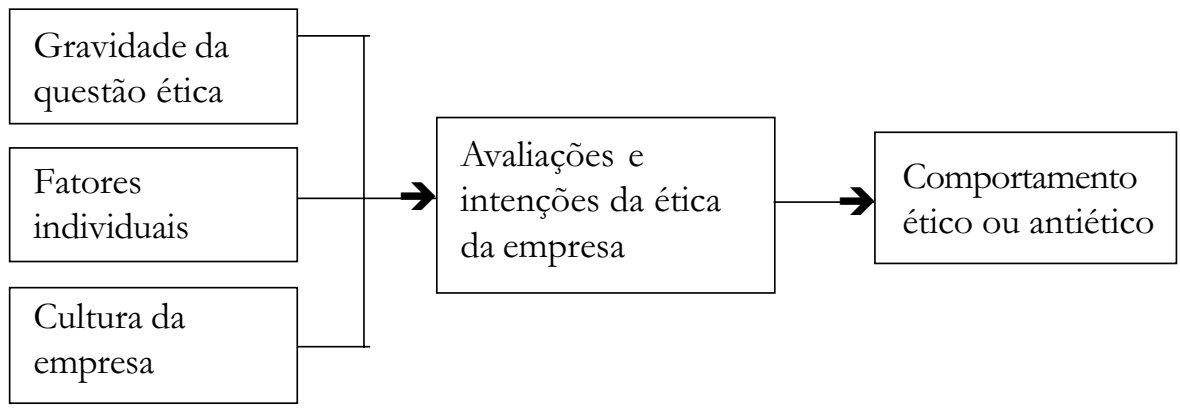

Figura 1. Modelo estrutural para compreender as tomadas de decisão ética na empresa. 
sofrem uma forte influência da ética sugerida e praticada nas organizações.

Optamos por empresas familiares porque elas representam a grande maioria das organizações empresariais de todo o mundo: 95 a 98\% das empresas estadunidenses e $96 \%$ das brasileiras, segundo Guerreiro (1996, citado em Souza \& Nunes, 1998). No Rio Grande do Sul, estas empresas também representam a maioria.

Não existe uma só definição para o que seja uma empresa familiar, mas os critérios mais utilizados para definir esta incluem, entre outros, que membros da familia possuam um percentual de quotas, bem como poder de voto, poder sobre decisões estratégicas e exista o envolvimento de várias gerações da família na execução dos trabalhos da empresa (Shanker \& Astrachan, 1996).

\section{Julgamento moral}

Por tratar-se da mais influente e contemporânea teoria do desenvolvimento moral, consideramos que a teoria de Kohlberg (1981) pode nos ajudar a entender e discutir alguns aspectos relacionados a problemática abordada nesta pesquisa - a ética e valores dos sujeitos nas empresas. Por isso resolvemos incluir também o aspecto relacionado ao julgamento moral e compará-lo com valores e éticas seguidos na empresa.

O modelo teórico de Kohlberg (1971) defende que os julgamentos e normas morais devem ser entendidos como construções universais dos agentes humanos que regulam as suas interações sociais, em vez de reflexões passivas de qualquer fato externo ou de emoções internas.

Os níveis de desenvolvimento dessa perspectiva sócio-moral, baseados em Kohlberg, possibilitam uma organização geral do julgamento moral e servem para informar e unir outros conceitos morais mais específicos, como a natureza do moralmente certo ou bom, reciprocidade moral, regras, direitos, obrigações ou deveres, eqüidade, conseqüências do bem-estar e valores morais como a obediência à autoridade, a preservação da vida, a manutenção de contratos e de relações afetivas (Colby \& Kohlberg, 1984).

Kohlberg (1964) organizou uma série de seis estágios e três níveis (pré-convencional, convencional, pós-convencional), dois estágios em cada nível, do desenvolvimento e articulação do julgamento moral, que se estende da infância à vida adulta. Ele baseou o seu trabalho na classificação de tipos de raciocínio moral apresentados pelos indivíduos, quando eles eram confrontados com dilemas hipotéticos. A sua descrição vai do pré-moralismo, passa pelo conformismo e se estende até a moralidade de princípios individuais.

No primeiro nível, denominado pré-convencional, não existe internalização de princípios morais. $\mathrm{O}$ ato é julgado pelas suas conseqüências e não pelas suas intenções, pois os indivíduos não chegaram a entendere respeitar normas e expectativas compartilhadas. Este é característico da maioria das crianças com menos de 9 anos, de alguns adolescentes e de muito criminosos adolescentes e adultos (Kohlberg, 1964).

No segundo nível, chamado convencional, já existe a internalização, o indivíduo acredita no valor e no reconhecimento daquilo que julga por excelência. A moralidade consiste de regras morais, papéis e normas socialmente compartilhados. Este nível é o da maioria dos adolescentes e adultos da sociedade moderna americana (Colby \& Kohlberg, 1984).
No terceiro nível, conhecido por pós-convencional, há o questionamento das leis estabelecidas e o reconhecimento de que podem ser injustas e devem ser alteradas. As pessoas entendem e aceitam as regras da sociedade, mas essa aceitação se baseia na formulação de princípios morais gerais que sustentam essas regras. Seguem princípios de consciência e não pela convenção. Este nível é alcançado por uma minoria de adultos (em torno de $5 \%$ ), geralmente depois dos 20 anos (Kohlberg, 1964).

Os estágios de julgamento moral, propostos por Kohlberg (1964), dos quais dois estão compreendidos dentro de cada um dos níveis acima descritos, são os seguintes:

- Primeiro estágio - orientação para a punição e obediência: caracteriza-se pela moralidade do ato definida em termos de conseqüências físicas para o agente. Se a ação é punida, está moralmente errada; se não for punida, está correta.

- Segundo estágio - hedonismo instrumental relativista: a ação moralmente correta é definida em termos de prazer ou da satisfação das necessidades da pessoa. Este estágio é caracterizado pelo egoísmo, pela moral relativa e o ato moral é um instrumento de satisfação pessoal.

— Terceiro estágio - moralidade do bom garoto, de aprovação social e de relações interpessoais: o comportamento moralmente correto é aquele que leva à aprovação dos outros. Neste estágio surge a concepção da eqüidade. Lourenço (1992) comenta que neste estágio há uma orientação para a moralidade interpessoal, isto é, uma tendência para se agir de modo a ser bem visto aos olhos dos outros ou a merecer o seu respeito, estima e consideração.

- Quarto estágio - orientação para a lei e a ordem: existe o respeito pela autoridade, regras fixas e pela manutenção da ordem social. A justiça tem a ver com a ordem social estabelecida (indivíduo e sistema), e não é uma questão de escolha pessoal moral.

- Quinto estágio - orientação para o contrato social: o indivíduo admite que as leis ou costumes morais podem ser injustos e devem ser mudados pelos canais legais e contratos democráticos.

- Sexto estágio - princípios universais de consciência: o indivíduo reconhece os princípios morais universais da consciência individual e age de acordo com eles. Estas obrigações morais envolvem: princípio de justiça; princípio de "role-taking", ou seja, capacidade de se colocar no lugar do outro e o princípio do respeito pela personalidade.

\section{Valores}

Todo atitude ética inclui a necessidade de escolher entre vários atos possíveis. Esta escolha deve basear-se, por sua vez, em uma preferência. Escolhemos tomar tal atitude porque ela se apresenta como mais digna, mais elevada moralmente, ou mais valiosa.

Para Vázquez (2001), o valor não é propriedade dos objetos em si, mas ele só atinge propriedade graças à sua relação com o homem, enquanto sujeito social. Apesar de que os objetos também têm um valor em função de certas propriedade objetivas, é o homem - como ser histórico-social e a sua atividade prática - que cria os valores e os bens nos quais acreditam e seguem. Os valores são, portanto, criações humanas, e só existem e se realizam no homem e pelo homem. 
Segundo Leisinger e Schimitt (2001), valores são algo que possui unidade e perenidade; valores são as metas às quais a moral aspira metas que conferem à moral um objetivo. Nas metas está situada a exigência normativa, a partir da qual a moral experimenta sua justificação ou desqualificação - ou simplesmente, seu objetivo.

Para os mesmos autores, a moral é constituída por valores e normas. Onde as normas já pressupõe os valores e exigem que os mesmos sejam realizados. No entanto, com freqüência, as controvérsias éticas se ressentem do fato de parceiros não compartilharem os mesmos valores sobre os quais se fundamentam suas normas morais. $\mathrm{O}$ que para um pode representar um valor, pode para o outro ser um desvalor.

\section{Método}

\section{Participantes}

Em nossa pesquisa, optamos inicialmente, por investigar duas empresas gaúchas (Empresa 1 e Empresa 2), localizadas na região da grande Porto Alegre.

A Empresa 1 é uma empresa de produtos e serviços, de porte médio, com aproximadamente 410 colaboradores, que atua há mais de 35 anos no mercado nacional. Nesta, foram 28 participantes, sendo 16 do sexo masculino e 12 do sexo feminino. A faixa etária correspondeu à fase adulta. $\mathrm{O}$ tempo de empresa foi classificado em: até 2 anos, com 46,4\% dos participantes; de 2 a 5 anos, com 10,7\%, e, mais de 5 anos, com $42,9 \%$ dos participantes. Quanto à função na empresa, $17,9 \%$ exercem algum cargo de gestão e $82,1 \%$ não exercem.

A Empresa 2 é uma empresa de serviços, de grande porte, com aproximadamente 4600 colaboradores, atuando há mais de 50 anos no mercado nacional. Nesta, também foram 28 os participantes, sendo 21 do sexo masculino e 7 do sexo feminino. A faixa etária utilizada foi a fase adulta. $\mathrm{O}$ tempo de empresa foi classificado em: até 2 anos, com $17,9 \%$ dos participantes; de 2 a 5 anos, com $32,1 \%$, e, mais de 5 anos, com $50 \%$ dos participantes. Quanto à função na empresa, $39,3 \%$ exercem algum cargo de gestão e 60,7\% não exercem.

\section{Instrumentos}

Foi utilizado um questionário com questões fechadas, semi-abertas e abertas, que envolveram possíveis alternativas de escolhas éticas e valores priorizados no trabalho, elaboradas a partir da literatura revisada.

O instrumento utilizado para avaliar o nível de julgamento moral foi o Moral Judgment Intenvien (MJI- Kohlberg, 1964), traduzido para o português por Biaggio (1969). Neste estudo, adaptamos a forma de entrevista para questionário, sendo que as perguntas sobre $o$ julgamento moral compreenderam dois dilemas morais hipotéticos e cada dilema foi seguido por questões designadas para obter justificações, elaborações e clarificações dos julgamentos morais dos participantes.

\section{Procedimentos}

Primeiramente, fizemos contatos com as empresas, através de telefonemas, e agendamos visitas onde o projeto e o instrumento foram apresentados. Posteriormente, ocorreram as aplicações dos questionários em grupo, nesta ocasião foi utilizado um Termo de Consentimento Livre e Esclarecido, com o objetivo geral da pesquisa e da participação de forma voluntária e confidencial. Também foi oferecida para as empresas uma devolução dos seus respectivos resultados.

\section{Análise dos dados}

A metodologia utilizada para avaliar os questionários, nas questões abertas, foi a análise de conteúdo, baseada no referencial de Bardin (1977). Esta análise compreende as seguintes etapas: leitura do material, criação de categorias abrangentes, codificação em unidades de descrição e contagem de frequêencia de aparição de cada unidade. Para perguntas fechadas do questionário, utilizamos a análise de frequêencia das respostas, realizada através do pacote estatístico SPSS. Portanto, utilizamos na análise dos dados tanto métodos qualitativos (análise de conteúdo), como métodos quantitativos (contagem de frequêencia das categorias).

Para verificarmos a respeito do julgamento moral dos participantes, sorteamos aleatoriamente 16, sendo 4 com e 4 sem cargos de gestão em cada empresa.

As questões foram avaliadas de acordo com a última versão do manual (Colby \& Kohlberg, 1987), onde procura-se um critério que seja igual ou análogo ao dado pelo participante e classifica-se a resposta em estágio. Depois se calcula um escore baseado na média de todas as respostas, com um sistema de pesos, que dá a classificação do nível de julgamento moral preponderante.

\section{Resultados}

Nas questões abertas do questionário obtivemos as categorias descritas abaixo.

Pergunta sobre o que é ética

Empresa 1

- 45,4\% relacionaram a ética a comportamentos que temos no dia-a-dia, como: agir corretamente, ser honesto, não prejudicar os outros e ser humilde.

- 36,4\% associaram a ética a padrões morais como: questão de honestidade, saber o que é certo ou errado, respeitar normas e ter respeito.

- 18,2\% referiram a ética no trabalho como: avaliar um funcionário pela competência e freqüência; dedicar-se ao trabalho; respeitar os compromissos, colegas e clientes; ter uma conduta profissional e seguir a política da empresa.

Empresa 2

- 56,1\% associaram a ética a padrões morais como: saber julgar o que é certo ou errado agir conforme a sociedade, agir segundo o seu julgamento, seguir normas, ser moral, respeitar pessoas ou organizações e sofrer influência cultural e pessoal.

- 29,3\% relacionaram a ética a comportamentos que temos no dia a dia, como: ser honesto com responsabilidade, ter bom comportamento pessoal e/ou empresarial e fazer as coisas certas.

- 14,6\% referiram a ética no trabalho como: ser profissional, ter discrição, saber o que podemos comentar, respeitar as normas e regras e não ultrapassar os limites da empresa. 


\section{Exemplos de atitudes éticas em uma empresa}

Empresa 1

- $69 \%$ relacionaram estas atitudes à ética pessoal: colaborar com o grupo, não prejudicar, ajudar e respeitar os outros, não roubar, ser educado, sincero, honesto e amigo, ter interesse em aprender, desempenhar bem suas tarefas e ter entusiasmo durante o expediente.

- $31 \%$ associaram estas atitudes à ética empresarial: comportarse dentro das normas da empresa, ter conhecimento técnico, ser reconhecido por sua competência, colaborar com o grupo para o êxito do trabalho e realizar um bom trabalho.

\section{Empresa 2:}

- 63\% associaram estas atitudes à ética empresarial, como: agir de forma correta conforme as normas estabelecidas, seguir padrões de qualidade, respeitar funcionários e pessoas, a empresa deve deixar claro para os funcionários a sua política, deve dar punições e vantagens iguais para todos, cumprir contratos, prestigiar funcionário pelo desempenho e tempo de empresa, fazer negociações claras e lícitas, pagar salário digno, oferecer auxilio ambulatorial e possuir bom ambiente para a realização do trabalho.

- 37\% relacionaram estas atitudes à ética pessoal, como: fazer seu serviço bem feito para não prejudicar o colega, não roubar, tratar os problemas apenas com as pessoas envolvidas, assumir os erros, ser honesto, seguir e conquistar seus objetivos sem perder seus valores, ouvir opiniões, não ter preconceito e entender o outro, colocando-se em seu lugar.

\section{Exemplos de atitudes antiéticas em uma empresa}

Empresa 1

— $79 \%$ relacionaram estas atitudes à ética pessoal, como: não colaborar com o grupo visando à promoção pessoal, assumir tarefas que não tenha conhecimento técnico, prejudicar os outros, desatenção, inimizade, desinteresse, falta de educação e de moral, usar idéias de colegas para se promover, furtar, mentir, fazer coisas erradas às escondidas, falar de alguém, esbanjar material e aproveitar-se de posição hierárquica.
- 21\% associaram estas atitudes à ética empresarial, como: comportar-se fora das normas da empresa, não comentar projetos da empresa com funcionários, enganar clientes, valorizar funcionários somente pelo tempo de empresa e não pela competência, subornar.

Empresa 2

- 56\% relacionaram estas atitudes à ética pessoal, como: fazer uso do cargo para benefício próprio, roubar, não respeitar os princípios da empresa, comentar com outros os problemas que acontecem dentro de sua equipe, não assumir os seus erros, denegrir a ética de outra pessoa, funcionários que ocupam o seu tempo com atividades que não são da empresa, dizer palavrões para funcionários, aproveitar-se do sofrimento de outras pessoas, mentir para chefias, desviar equipamentos da empresa e não ser leal com o colega.

- 44\% associaram estas atitudes à ética empresarial, como: ser explorador, não ouvir, desrespeitar, desvalorizar e dar tarefas que humilhem os funcionários, faltar com o compromisso para com o cliente, vender produtos falsificados, favorecimento de promoções sem critérios claros, subornar, não cumprir com as obrigações fiscais e trabalhistas e prejudicar o meio ambiente.

Nas questões fechadas, que dizem respeito à cultura das empresas, obtivemos os dados referentes a Tabela 1, os quais destacamos que: ambas empresas possuem código de ética e este é conhecido pela maioria dos seus funcionários e em ambas empresas quando ocorre uma infração a punição não é igual para todos.

Já quanto a avaliação de alguns itens como qualidade do produto, relação com o cliente, rotatividade, etc., podemos observar nas Tabelas 2 e 3 que a maioria dos itens receberam a classificação de bom em ambas as empresas.

Quanto às situações éticas, podemos considerar que na Empresa 1, 100\% dos participantes mencionaram que raramente ou nunca ocorrem: falsificação de registros e documentos; o consumo de álcool e/ou de drogas durante o expediente; a aceitação de presentes ou de pagamento por vantagens; o suborno para obtenção de contratos, serviços ou vantagens; o prejuízo da segurança e da qualidade do produto para baixar o seu custo. E na Empresa 2, 100\% citaram que raramente ou nunca ocorrem: o suborno para obtenção de contratos,

Tabela 1

Questões Referentes à Cultura

\begin{tabular}{|c|c|c|c|c|}
\hline \multirow[b]{2}{*}{ Questão } & \multicolumn{2}{|c|}{ Empresa 1} & \multicolumn{2}{|c|}{ Empresa 2} \\
\hline & Sim & Não & $\operatorname{Sim}$ & Não \\
\hline A empresa possui um código de ética & $89,3 \%$ & $3,6 \%$ & $82,1 \%$ & $17,9 \%$ \\
\hline A ética da empresa é conhecida pelos funcionários & $82,1 \%$ & $17,9 \%$ & $78,6 \%$ & $21,4 \%$ \\
\hline Concordo com a maioria dos princípios éticos da empresa & $82,1 \%$ & $17,9 \%$ & $71,4 \%$ & $25,0 \%$ \\
\hline A empresa deixa claro quais são os direitos e deveres praticados & $89,3 \%$ & $10,7 \%$ & $85,7 \%$ & $14,3 \%$ \\
\hline A empresa é aberta a sugestões e críticas quanto as normas adotadas & $78,6 \%$ & $17,9 \%$ & $53,6 \%$ & $42,8 \%$ \\
\hline $\begin{array}{l}\text { A empresa informa a todos sobre seus objetivos/missão e a cultura } \\
\text { praticados }\end{array}$ & $71,4 \%$ & $25,0 \%$ & $85,7 \%$ & $14,3 \%$ \\
\hline $\begin{array}{l}\text { A empresa divulga quais são as penalidades que podem ser adotadas } \\
\text { quanto a infrações/erros }\end{array}$ & $39,3 \%$ & $57,1 \%$ & $53,6 \%$ & $42,8 \%$ \\
\hline $\begin{array}{l}\text { Os investimentos da empresa em atividades sociais aumentaram nos } \\
\text { últimos anos }\end{array}$ & $71,4 \%$ & $17,9 \%$ & $64,3 \%$ & $32,1 \%$ \\
\hline $\begin{array}{l}\text { Na empresa quando ocorre uma infração a punição é igual para todos } \\
\text { os funcionários }\end{array}$ & $25,0 \%$ & $53,6 \%$ & $35,7 \%$ & $60,7 \%$ \\
\hline
\end{tabular}

Psicologia: Reflexão e Crítica, 2005, 18(2), pp.237-246 
Tabela 2

Avaliação de Alguns Itens na Empresa 1

\begin{tabular}{lcrr}
\hline Item & Ótimo & Bom & Ruim \\
\hline Qualidade do produto e do serviço & $21,4 \%$ & $75,0 \%$ & $3,6 \%$ \\
Compromisso do empregado com estratégia e visão da empresa & $17,9 \%$ & $61,7 \%$ & $21,4 \%$ \\
Relações com o cliente e fidelidade do consumidor & $32,1 \%$ & $57,2 \%$ & $10,7 \%$ \\
Relacionamento dos grupos de trabalho & $28,6 \%$ & $67,5 \%$ & $3,6 \%$ \\
Rotatividade dos funcionários & $14,3 \%$ & $57,1 \%$ & $28,6 \%$ \\
Funcionamento dentro da empresa no dia-a-dia & $32,1 \%$ & $60,8 \%$ & $7,1 \%$ \\
\hline
\end{tabular}

Tabela 3

Avaliação de Alguns Itens na Empresa 2

\begin{tabular}{lccc}
\hline Item & Ótimo & Bom & Ruim \\
\hline Qualidade do produto e do serviço & $39,3 \%$ & $60,7 \%$ & - \\
Compromisso do empregado com estratégia e visão da empresa & $14,3 \%$ & $85,7 \%$ & - \\
Relações com o cliente e fidelidade do consumidor & $50,0 \%$ & $50,0 \%$ & - \\
Relacionamento dos grupos de trabalho & $17,9 \%$ & $71,4 \%$ & $10,7 \%$ \\
Rotatividade dos funcionários & $17,9 \%$ & $50,0 \%$ & $32,1 \%$ \\
Funcionamento dentro da empresa no dia-a-dia & $25,0 \%$ & $75,0 \%$ & - \\
\hline
\end{tabular}

serviços ou vantagens e a apresentação enganosa de características do produto.

Os participantes citaram como as infrações mais cometidas por funcionários na Empresa 1: 17,9\% mentem; 7,1\% roubam ou furtam e desviam equipamentos da empresa para prestação de serviços particulares. $\mathrm{Na}$ Empresa 2, foram mencionadas: 28,6\% roubam ou furtam; $14,3 \%$ mentem; 7,1\% aceitam presentes ou pagamentos por vantagens e cometem assédio sexual; 3,6\% consomem álcool e/ou drogas durante o expediente, prometem entrega que não poderia ser feita no prazo marcado, falsificam registros e documentos, cometem o suborno para obtenção de contratos, serviços ou vantagens, desviam equipamentos da empresa para prestação de serviços particulares e contratam, por indicação, pessoas não-qualificados ao cargo.

Já para as chefias, apareceram as seguintes infrações na Empresa 1: $17,9 \%$ contratam por indicação pessoas não-qualificados ao cargo; $14,3 \%$ escondem informações importantes sobre as empresa e dão ordem a funcionários que não estejam sob sua supervisão; 10,7\% prometem entrega que não poderia ser feita no prazo marcado. E na Empresa 2, novamente foram levantadas maior número de infrações tais como: $21,4 \%$ prometem entrega que não poderia ser feita no prazo marcado e dão ordem a funcionários que não estejam sob sua supervisão; $14,3 \%$ dão preferência a resultados a curto prazo sem considerar as conseqüências ou danos que eles possam causar e controlam e fiscalizam recados e e-mails, $10,7 \%$ exigem horas-extras e trabalho em fins-de-semana, sem pagamento adicional; 7,1\% contratam por indicação pessoas nãoqualificadas ao cargo e não informam os empregados sobre problemas de saúde e segurança no local de trabalho; 3,6\% mentem, cometem assédio sexual, desviam equipamentos da empresa para prestação de serviços particulares, escondem informações importantes sobre as empresa.

Finalmente, apareceram para a direção, quanto às infrações mais realizadas, na Empresa 1: 25\% prometem entrega que não poderia ser feita no prazo marcado; $17,9 \%$ dão preferência a resultados a curto prazo sem considerar as conseqüências ou danos que eles podem causar; $14,3 \%$ escondem informações importantes sobre as empresa; $10,7 \%$ contratam por indicação pessoas não-qualificadas ao cargo e desviam pessoal interno em horário de expediente para prestação de serviços particulares. E na Empresa 2 apareceram: 14,3\% escondem informações importantes sobre as empresa; $10,7 \%$ desviam equipamentos da empresa para prestação de serviços particulares, dão preferência a resultados a curto prazo sem considerar as conseqüências ou danos que eles podem causar; 7,1\% dão ordem a funcionários que não estejam sob sua supervisão, contratam por indicação pessoas não-qualificadas ao cargo e desviam pessoal interno em horário de expediente para prestação de serviços particulares; $3,6 \%$ prometem entrega que não poderia ser feita no prazo marcado.

No que diz respeito a quando acontece uma má conduta na empresa, as respostas mais freqüentes em ambas foi a de que a empresa adotaria uma medida corretiva (75\% na Empresa 2 e 54,3 \% na Empresa 1). Já quanto a uma má conduta, acreditase que ela sempre deve ser denunciada, sendo que a maioria acha que não há razão justificável para não se denunciar o cometimento dessa falha (Tabela 4).

Quanto aos fatores da ética pessoal mencionados pelos participantes, como sendo os mais importantes, para justificar os comportamentos utilizados dentro do trabalho, os dois mais votados em ambas empresas foram, respectivamente na Empresa 1 e 2: consideram as conseqüências que suas ações podem produzir para as pessoas $(35,7 \% ; 32,1 \%)$ e buscam respeitar às regras e normas morais que a ação envolve $(25 \% ; 28,6 \%)$.

No que diz respeito aos valores, quando conflitos aparecem (ver Tabelas 5 e 6), os participantes acreditam que devem dar mais importância à família, clientes e interesses pessoais, sendo que a empresa foi citada com menor destaque. 
Tabela 4

Razões que Justificariam Fato de não Denunciar a Má Conduta

Disseram que não existe razão pois a má conduta deve ser denunciada

Mencionaram que não acreditam que medidas corretivas sejam aplicadas

Não acreditam que a empresa mantenha a denúncia em sigilo

Não denunciariam por medo de não ser considerado um bom componente da equipe

Têm receio de vingança do chefe ou da alta administração

Opinaram que ninguém preocupa-se com ética empresarial, por que eles então se preocupariam?

Mencionaram outras alternativas, ex.: se prejudicasse o trabalho denunciaria.

Anularam a questão

\begin{tabular}{cc} 
Empresa 1 & Empresa 2 \\
$53,6 \%$ & $67,9 \%$ \\
$14,3 \%$ & - \\
$10,7 \%$ & $3,6 \%$ \\
$10,7 \%$ & $14,3 \%$ \\
$7,14 \%$ & $7,1 \%$ \\
$3,6 \%$ & - \\
- & $3,6 \%$ \\
- & $3,6 \%$ \\
\hline
\end{tabular}

Tabela 5

Ordem de Importancia quando Conflitos Aparecem na Empresa 1

\begin{tabular}{lclrlc}
\hline Muita importância & $\%$ & Alguma importância & $\%$ & Nenhuma importância & $\%$ \\
\hline família & 71,4 & amigos & 46,4 & nação & 39,3 \\
cliente & 46,4 & interesses pessoais & 42,9 & & \\
empresa & 42,9 & religião & 21,4 & & \\
humanidade & 25,0 & & & & \\
\hline
\end{tabular}

Tabela 6

Ordem de Importancia quando Conflitos Aparecem na Empresa 2

\begin{tabular}{lclc}
\hline Muita importância & $\%$ & Alguma importância & $\%$ \\
\hline família & 92,9 & empresa & 64,3 \\
interesses pessoais & 46,4 & chefia e autoridade & 42,9 \\
cliente & 39,3 & religião, amigos e nação & 35,7 \\
& & humanidade & 28,6 \\
\hline
\end{tabular}

Tabela 7

Médias do Nivel de Julgamento Moral

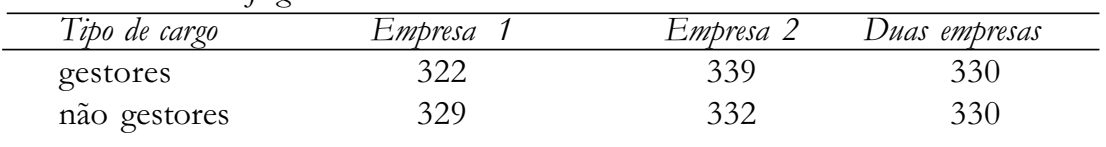

Quanto aos valores que consideram mais importantes seguir dentro da empresa, foram destacados na Empresa 1: por 89,29\% dos participantes a responsabilidade e o respeito; por $82,14 \%$ a honestidade; por $71,43 \%$ a honra; por $57,14 \%$ a humildade e por 53,57\% a justiça. Na Empresa 2 foi mencionado por 92,9\% das pessoas a honestidade; por $71,4 \%$ o respeito; por $67,9 \%$ a honra e a responsabilidade ; por $64,3 \%$ a justiça e por $53,6 \%$ a humildade.

Quanto aos valores que participantes acreditam que a empresa considera mais importante seguir, foram apontados na Empresa 1: por $78,57 \%$ dos participantes a responsabilidade, respeito e honestidade; por $64,30 \%$ a honra; por $60,71 \%$ a humildade e por 53,57\% a justiça. Já na Empresa 2 apareceu por $92,9 \%$ das pessoas a honestidade; por $85,7 \%$ a responsabilidade; por $67,9 \%$ o respeito; por $57,1 \%$ a honra e por $53,6 \%$ a justiça.

Quanto ao nível de julgamento moral, podemos observar (Tabela 7) que não encontramos diferenças significativas nas médias obtidas no grupo de gestores e no de não gestores, sendo que quando comparadas as duas empresas juntas esta média é igual em ambos tipos de cargo.

\section{Discussão}

Os participantes de ambas empresas, ao conceituar ética, relacionaram esta a comportamentos que temos no dia-a-dia e a padrões morais, sendo que também referiram a ética no campo do trabalho.

Como exemplos de atitudes éticas e antiéticas em uma empresa, foram mencionados tanto aspectos relacionados à ética pessoal, como à ética empresarial, sendo que na Empresa 1 apareceram mais exemplos da ética pessoal e, na 2, mais da ética empresarial.

Como já foi citado anteriormente, dentro da empresa há duas vertentes em questão: a ética pessoal e a ética empresarial. Leisinger e Schimitt (2001) comentam que a ética individual e a ética empresarial não devem ser lançadas uma contra a outra. Não obstante, há um campo de tensões existente que pode ser descrito como: em uma empresa, quanto mais os colaboradores possuem espaço de decisão e de responsabilidade própria, tanto mais a ética empresarial é marcada pela ética individual; quanto mais fragmentados os cursos de ações e quanto mais autoritários, 
tanto mais a violência estrutural passa a ser um problema. Enfim, a empresa tem de conceder autonomia a seus colaboradores para que alcancem as metas propostas. Mas criar uma cultura empresarial que favoreça a moral e faça justiça às pessoas não é tarefa das instituições em si, mas das pessoas portadoras de responsabilidade em todas as posições importantes da empresa.

A moralidade ou a falta de moralidade, desta forma, é trazida para os sistemas através das pessoas, por suas orientações de valor e pela consistência de seus comportamentos. Evidentemente toda empresa desenvolve sua vida institucional própria, mas isto não diminui a responsabilidade dos indivíduos, antes a aumenta. Colaboradores de todos os níveis têm conhecimento técnico, experiência profissional e competência social. Por isso eles também têm o dever de responsabilizar-se por si, pelas pessoas a quem suas decisões afetam e pelas metas da empresa a serem alcançadas. Têm igualmente o dever de defender suas convicções morais. Enfim, os atores morais são, portanto, tanto a empresa como as pessoas que nelas trabalham, sendo que os participantes deste estudo demonstraram que têm consciência da sua parcela de contribuição no compromisso ético.

Foi destacado pelos participantes das duas empresas que elas possuem um código de ética e que este é conhecido pelos seus funcionários. Portanto, isto indicaria que ambas empresas estão engajadas na preocupação de ter uma ética empresarial e de estabelecer procedimentos e padrões para detectar e prevenir a má conduta (Ferrell \& cols., 2000/2001).

Para Moreira (1999), o Código de Ética é um padrão de conduta para pessoas com diferentes visões e experiências aplicadas a atividades empresariais complexas. Ele tem a missão de padronizar e formalizar o entendimento da organização empresarial em seus diversos relacionamentos e operações, evitando que os julgamentos subjetivos deturpem, impeçam ou restrinjam a aplicação plena dos princípios. Este ainda pode servir como prova legal da intenção da empresa. A maneira de fazer o Código ser cumprido consiste em estabelecer um Programa de Ética constituído por: treinamento de implantação e reciclagem (no mínimo anuais) dos conceitos constantes do Código; prática de um sistema de revisão e verificação do efetivo cumprimento; criação de um canal de comunicação destinado a receber e a processar relatos de pessoas (empregados ou não) sobre eventuais violações; tomada de atitudes corretivas ou punitivas em caso de constatação de violação; luta clara contra os concorrentes antiéticos, inclusive em juízo, se necessário, com divulgação interna das ações e resultados. Neste aspecto observamos que ambas empresas mantinham nas suas instalações textos com conteúdos referentes à visão e a missão da empresa, valores e padrões éticos sugeridos.

Apesar de ter sido citado pela maioria, que ambas empresas adotariam medidas corretivas para a má conduta e que esta deve ser denunciada, quase metade dos participantes mencionou que as empresas não divulgam quais são as penalidades que podem ser adotadas quanto às infrações e aos erros cometidos. No caso das empresas estudadas, parece que estas ainda não estão correspondendo a todas as condições esperadas nas medidas corretivas e por isso, deixam muito mais nas mãos das pessoas decidirem se vão ou não seguir os preceitos éticos e morais. Moreira (1999) afirma que as sanções mínimas e máximas, a que estarão sujeitos os violadores dos princípios, devem constar expressamente no Código de Ética da empresa.

Mais da metade dos participantes também apontou que quando ocorre uma infração a punição não é igual para todos os funcionários, o que indica um favorecimento de alguns em detrimento de outros. Tagiuri e Davis (1996, citado em Souza \& Nunes, 1998) acreditam que em empresas familiares, freqüentemente, ocorrem falhas na objetividade com que os assuntos são tratados, sendo estes decididos dentro de padrões das relações familiares.

As duas empresas aumentaram os investimentos em atividades sociais. Quanto a este aspecto, Leisinger e Schimitt (2001) comentam que as empresas possuem deveres econômicos, sociais e ecológicos entre os quais podemos citar: engajar-se em favor do contexto social, apoiar as comunidades e assumir responsabilidade social. Já Ferrell e colaboradores (2000/2001) mencionam que existe a expectativa de que as empresas contribuam de alguma forma para as comunidades locais, visando à qualidade de vida e o bem-estar destas. Estes investimentos podem ser em dinheiro ou em serviços prestados à comunidade. Srour (2000) acrescenta ainda, que é fundamental se questionar a respeito de duas questões: Que tipo de contribuição nós, como empresa, damos ou podemos dar à sociedade? Em que medida é ela positiva ou negativa?

Quanto às infrações cometidas por funcionários nas empresas, as mais citadas foram: mentira, roubo, desvio de equipamento, aceitação de presentes, assédio sexual e consumo de álcool e drogas durante o expediente. Sendo que esta última infração coloca em risco a segurança do trabalho pelo tipo de atividade exercida na Empresa 2.

Quanto às infrações cometidas por chefias, encontramos: contratar por indicação pessoas não-qualificadas ao cargo, esconder informações sobre a empresa, prometer entrega que não poderia ser feita no prazo marcado, controlar recados e e-mails, dar preferência a resultados a curto prazo sem considerar as conseqüências ou danos que eles podem causar, exigir horas extras sem pagamento adicional. Sendo que esta última é considerada descumprimento da lei trabalhista atualmente vigente em nosso país.

Já a direção, segundo os participantes, pratica as seguintes infrações: prometer entrega que não poderia ser feita no prazo marcado, dar preferência a resultados a curto prazo sem considerar as conseqüências ou danos que eles podem causar, esconder informações importantes sobre as empresa, contratar por indicação pessoas não-qualificadas ao cargo e desviar pessoal interno e equipamentos em horário de expediente para prestação de serviços particulares.

Para Moreira (1999), a empresa ética expõe a verdade ao empregado e permite o acesso deste aos dados que a ele se referem. $O$ respeito à privacidade implica em: não violação das correspondências e comunicações do empregado, utilização de bancos de dados públicos para pesquisa sobre o empregado e não interferir na vida pessoal do empregado.

É interessante observar que nos três grupos as infrações citadas, por categoria, foram bastante semelhantes nas duas empresas. Mas cabe ainda ressaltar que estes resultados encontrados nas empresas, quanto às infrações citadas, podem ser analisados separadamente, de acordo com as especificidades de cada uma. A Empresa 2 apresentou maior número de infrações citadas nos três grupos: funcionários, 
chefias e direção, sugerindo ser menos ética do que a Empresa 1. Podemos pensar que isto pode ser devido ao fato da Empresa 2 ter aproximadamente 4600 colaboradores, enquanto que a Empresa 1 tem cerca de 410, o que dificulta o acompanhamento e a divulgação dos critérios éticos sugeridos pela empresa. Ferrell e colaboradores (2000/2001) sugerem que é importante monitorar o cumprimento dos padrões éticos dos funcionários, comparando seus desempenhos com os padrões éticos da empresa, o que pode ser feito mediante a observação da conduta dos empregados, incentivando nestes um enfoque pró-ativo de lidar com os problemas éticos, através de auditorias, questionários que avaliam como os funcionários vêem a empresa e treinamentos constantes. Também para manter uma conduta ética, a alta administração precisa dar exemplo e apoio constantes.

Quando ocorrem conflitos de interesses as pessoas dão preferência à familia, aos clientes e aos interesses pessoais e, por último, à empresa. Sendo que a nação não teria nenhuma importância, isto pode indicar um descrédito em relação ao Governo Federal. É interessante ressaltar que a pesquisa foi realizada no período anterior as eleições de 2002.

Também podemos mencionar que duas pesquisas de âmbito nacional, feitas pelo Ibope no fim de 1992 e início de 1993, registraram que $64 \%$ dos entrevistados consideravam que, no Brasil, quando uma pessoa tem a oportunidade de conseguir uma vantagem fazendo algo errado, e sabe ter poucas chances de ser descoberta, ela age ilegalmente. E mais: 65\% acreditam que o povo brasileiro é desonesto; $82 \%$ consideram que a maioria das leis não é obedecida; $86 \%$ acharam que existem certas pessoas que, mesmo que façam coisas erradas, nunca serão punidas pela Justiça; 80\% acreditam que as leis só existem para os pobres e que a Justiça brasileira não trata os pobres e ricos da mesma maneira (Srour, 2000). Estas pesquisas também apontam para um certo descrédito com a nação brasileira.

No Brasil, enfrentamos uma crise ética que trata da perda dos valores que fundam e mantêm íntegra uma comunidade. Com certeza muitas vezes nos questionamos: será que vale a pena ser ético ou agir em nome de sólidos princípios ou, ainda, sobrepor a visão coletiva ao interesse individual? Por isto, a discussão ética vem como uma necessidade vital de a sociedade reconhecer a crise em sua dimensão plena, para ser capaz de acreditar que é possível alcançar o sucesso agindo eticamente.

Já no que diz respeito ao nosso Estado, a Federação das Associações Empresariais do Rio Grande do Sul (Federasul) em parceria com a Assembléia Legislativa do Rio Grande do Sul, preocupadas em discutir este tema e incentivar condutas exemplares, organizaram um livro que reúne narrativas sobre personalidades gaúchas que possuem compromisso com a ética. Nesta obra Elmi (2002) relata que há um senso mais ou menos estabelecido de que no contexto brasileiro, os gaúchos são exemplos de correção de atitude e respeito, de luta sincera por ideais. Menciona também que no Rio Grande do Sul foram erguidas empresas que se impuseram no mercado nacional e internacional, operando dentro de padrões avançados e corretos, sem abrir mão da ousadia, que é a essência do empreender. Diz ainda que, ninguém pode negar que a população gaúcha é pioneira na consciência da ação social e de que, ao Sul do Brasil, produz-se uma cultura altiva, enraizada, dinâmica e provocativa.
Os participantes, no que diz respeito à ética pessoal, considerariam primeiro as conseqüências de suas ações para as pessoas, a ética da responsabilidade, e depois o respeito a regras e normas, a ética da convicção. Neste aspecto Srour (2000) destaca que a ética da responsabilidade (estudo dos fins humanos) diz que somos responsáveis por aquilo que fazemos e a ética da convicção (tratado dos deveres) é pautada por valores e normas previamente estabelecidas, cujo efeito primeiro consiste em moldar as ações que deverão ser praticadas. As duas éticas enfocam tipos diferentes de referências morais e configuram, de forma inconfundível, dois modos de decidir. Enquanto os agentes que obedecem à ética da convicção guiam-se por imperativos de consciência, os que se orientam pela ética da responsabilidade guiam-se por uma análise de riscos.

Quanto aos valores que consideram mais importante seguir dentro da empresa e aqueles que a empresa considera mais importante seguir, foram destacados os mesmos valores: responsabilidade, respeito e honestidade. Os valores compartilhados por uma empresa são definições a respeito do que é importante para atingir o sucesso, indicam aquilo que é prioritário, comunicam o que se deve esperar da organização e estão relacionados a comprometimento, comportamento ético, autoconfiança em relação aos objetivos organizacionais (Srour, 2000).

Quanto ao nível de julgamento moral, o fato de não encontrarmos diferenças significativas, nas médias obtidas no grupo de gestores e no de não gestores, pode ter sido por termos adaptado a entrevista do MJI para a forma de questionário, sendo que os participantes escreveram e justificaram pouco as suas posições nos conflitos morais, o que dificultou a interpretação do nível de julgamento moral. Por isso, tivemos que eliminar alguns questionários e acabamos ficando com uma amostra menos representativa. Um estudo anterior sobre o nível de julgamento moral no Brasil, desenvolvido por Biaggio (2002) com adultos, indicou que os níveis de julgamento moral dos brasileiros distribuíram-se mais uniformemente entre os estágios 2, 3, 4 e 5, enquanto que nos americanos o estágio 4, foi dominante. Em outro estudo, onde foram comparados o nível de julgamento moral de americanos, mexicanos e brasileiros, na amostra brasileira, na faixa etária de 18 anos, predominou o estágio 3. No nosso estudo, os dados encontrados na média de ambos grupos correspondeu ao estágio 3, o que corrobora em parte os estudos citados acima.

O estágio 3, segundo Kohlberg (1964), corresponde a moralidade do bom garoto, de aprovação social e de relações interpessoais, onde o comportamento moralmente correto é aquele que leva à aprovação dos outros e há uma orientação para a moralidade interpessoal, isto é, uma tendência para se agir de modo a ser bem visto aos olhos dos outros ou a merecer o seu respeito, estima e consideração. Este dado a respeito do estágio 3 parece também corroborar um outro resultado encontrado a respeito da preferência dada à familia quantos existe conflitos de valores e menor importância concedida à humanidade pelos participantes da pesquisa. Esta última seria bastante considerada no estágio 6 como descreveremos logo abaixo.

Podemos pensar que em relação à teoria do julgamento moral de Kohlberg, o estágio mais indicado para que os funcionários seguissem à ética da empresa e não a sua ética pessoal seria o estágio 4 - orientação para a lei e a ordem- onde existe o respeito pela autoridade, regras fixas e pela manutenção da ordem social. 
Nesta concepção de julgamento moral, a justiça tem a ver com a ordem social estabelecida (indivíduo e sistema) e não é apenas uma questão de escolha pessoal moral.

Já o estágio 6 seria aquele onde os funcionários se guiariam mais pela sua ética pessoal, já que a formulação teórica do sexto estágio envolve decisões de consciência que incorporam: o senso Kantiano de justiça; a noção de universalidade dos deveres básicos; a noção do valor moral intrínseco a certas normas como salvar uma vida humana e manter uma promessa; e a noção da "lei moral" como mais elevada do que a da "lei legal" quando as duas entram em conflitos (Kohlberg, Boyd \& Levine, 1990).

Podemos observar a partir do que foi exposto acima que, para Kohlberg, a essência da moralidade reside mais no sentido amplo de justiça do que, propriamente, no respeito pelas normas morais. Portanto a moralidade tem mais a ver com considerações de igualdade, de equiidade, de contratos sociais e de reciprocidade nas relações humanas do que com o cumprimento ou violação de normas sociais ou até morais. De fato poderia haver circunstâncias em que teríamos que violar códigos morais empresariais para sermos justos, ou seja, para considerar a pessoa e os seus direitos fundamentais como um valor que não admite ser questionado.

\section{Conclusão}

Neste estudo pudemos refletir a respeito de condutas e éticas que vem sendo adotadas em duas empresas familiares gaúchas, mas certamente não nos propomos a esgotar um assunto tão complexo e amplo. Sendo que estes dados não podem ser generalizados para outras amostras.

Observamos que já existe uma preocupação ética em ambas empresas, visto que em ambas há um Código de Ética, mas também ocorrem vários tipos de infrações éticas em todos os níveis hierárquicos, o que indica que é necessário aprimorar a divulgação de valores e condutas a serem seguidas nas empresas.

Acompanhando Moreira (1999) achamos pertinente que para o Código de Ética ser cumprido é preciso estabelecer um Programa de Ética constituído por: treinamento de implantação e reciclagem (no mínimo anuais) dos conceitos constantes do Código; prática de um sistema de revisão e verificação do efetivo cumprimento; criação de um canal de comunicação destinado a receber e a processar relatos de pessoas (empregados ou não) sobre eventuais violações; tomada de atitudes corretivas ou punitivas em caso de constatação de violação; luta clara contra os concorrentes antiéticos, inclusive em juízo, se necessário, com divulgação interna das ações e resultados.

Ferrell e colaboradores (2000/2001) sugerem que é importante monitorar o cumprimento dos padrões éticos dos funcionários, comparando seus desempenhos com os padrões éticos da empresa, o que pode ser feito mediante a observação da conduta dos empregados, incentivando nestes um enfoque pró-ativo de lidar com os problemas éticos, através de auditorias, questionários que avaliam como estes vêem a empresa e treinamentos constantes. Também para manter uma conduta ética, a alta administração precisa dar exemplo e apoio constantes.

Biaggio (2002) sugere que a teoria de Kohlberg sobre o julgamento e desenvolvimento moral, ainda parece ser a que melhor se presta para fundamentar uma educação moral nas pessoas que promova os valores de justiça, bondade, solidariedade, respeito aos outros seres humanos e à natureza, o que seria também uma grande contribuição para melhorar os padrões éticos e morais vigentes na empresa. Para isto poderia quem sabe ser utilizada a técnica de discussão de dilemas morais em grupo, visando à promoção do desenvolvimento moral.

Sentimos a necessidade de que mais pesquisas sejam desenvolvidas nesta temática pois encontramos poucos estudos acerca da realidade brasileira sobre ética e valores nas empresas familiares.

\section{Referências}

Bardin, L. (1977). Análise de conteído. São Paulo: Martins Fontes.

Biaggio, A. M. B. (1969). Internalized versus externalized guilt: A cross-cultural study. Journal of Social Psychology, 73, 147-149.

Biaggio, A. M. B. (2002). Lawrence Koblberg: Ética e educação moral. São Paulo: Moderna.

Colby, A. \& Kohlberg, L. (1984). Invariant sequence and internal consistency in moral judgments stages. Em W. M. Kurtines \& J. L. Gewirtz (Orgs.), Morality, moral behavior, and moral development (pp. 41-51). New York: A Wiley-Interscience.

Elmi, A. (2000) (Org.). Éticas: Histórias de líderes e vencedores (2000). Porto Alegre: Assembléia Legislativa do Estado do Rio Grande do Sul/ Federasul.

Ferrell, O. C., Fraedrich, J. \& Ferrell, L. (2001). Ética empresarial: Dilemas, tomadas de decisões e casos ( $4^{\mathrm{a}} \mathrm{ed}$.). Rio de Janeiro: Reichmann \& Affonso.

Goulart, I. B. (2002) (Org.). Psicologia organizacional e do trabalho: Teoria, pesquisa e temas correlatos. São Paulo: Casa do Psicólogo.

Kohlberg, L. (1964). Development of moral character and moral ideology. Em M. L. Hoffman \& L. W. Hoffman (Orgs.), Review of child development research. (Vol. I; pp. 383-431). New York: Russel Sage Foundation.

Kohlberg, L. (1971). From is to ought: How to commit the naturalist fallacy and get away with it in the study of moral development. Em T. Machiel (Org.), Cognitive development and epistemology (pp. 123-150). New York: Academic Press.

Kohlberg, L. (1981). The philosophy of moral development. San Francisco: Harper \& Row.

Kohlberg, W., Boyd, D. R. \& Levine, C. (1990). The return of stage 6: Its principle and moral point of view. Em T. E. Wren (Org.), The moral domain: Essays in the ongoing discussion between philosophy and the social sciences (pp. 151-181). Massachutetts: The MIT Press.

Leisinger, K. M. \& Schmitt, K. (2001). Ética empresarial: Responsabilidade global e gerenciamento moderno. Petrópolis, RJ: Vozes.

Lourenço, O. M. (1992). Psicologia do desenvolvimento moral: Teoria, dados e implicações. Coimbra: Almedina.

Moreira, J. M. (1999). A ética empresarial no Brasil. São Paulo: Pioneira.

Shanker, M. \& Astrachan, J. (1996). Myths and realities: Families businesses contribuition to the US economy: A framework for assessing family business statistics. Family Business Review, IX,107-119.

Souza, Y. S. \& Nunes, M. L. T. (1998) (Orgs.). Familia, organizacões e aprendizagem: Ensaios temáticos em Psicologia. Porto Alegre: PUCRS.

Srour, R. H. (2000). Ética empresarial. Rio de Janeiro: Campus.

Vázquez, A. S. (2001). Ética (21 a ed.). Rio de Janeiro: Civilização Brasileira.

Weber, M. (1959). Le savant et le politique. Paris: Union Générale.

Recebido: 01/09/2003

$1^{a}$ Revisão: $20 / 11 / 2003$

Última Revisão: 03/05/2004

Aceite Final: 14/05/2004

Sobre as autoras

Janine Kieling Monteiro é Doutora em Psicologia do Desenvolvimento pela Universidade Federal do Rio Grande do Sul e Professora da Universidade do Vale do Rio dos Sinos.

Fabiana Cobas do Espirito Santo é Psicóloga.

Franciela Bonacina é aluna de graduação do curso de Psicologia da Universidade do Vale do Rio dos Sinos. 